\title{
Evaluation of Achillea millefolium essential oil compounds and biological effects on cervix cancer HeLa cell line
}

\author{
Mustafa Burak Acar ${ }^{1,2}$, Ebru Karadaş İbiş ${ }^{1,2}$, Ahmet Şimşek ${ }^{1}$, Cem Vural ${ }^{1,3}$, Coşkun Tez ${ }^{1,3}$ \\ and Servet Özcan ${ }^{1,3 *}$
}

\begin{abstract}
Yarrow essential oil is used in complementary and alternative therapy for several diseases. Biological effects of essential oils span various cells and microorganisms. The aim of this study was to investigate the effects of different concentrations of the essential oil obtained from the yarrow plant (Achillea millefolium) on HeLa (CCL-2) cells. The components of the essential oil were studied by means of GC-MS analysis. Out of 10 determined compounds in the essential oil; 1,8-Cineole, Camphor, Beta-eudesmol and Camphene were found to be higher than others; and their biological effects were depicted with Ingeniuty Pathway Analysis (IPA) analysis. Moreover, cell cycle and proliferation tests were conducted on HeLa cells where yarrow plant's essential oil was used. When extracted yarrow oil applied on HeLA Cells, apoptotic effects had been determined, furthermore proliferation of these cells decreased. In addition, activation of cell cycle control points was observed. Essential oil components could arrest the development of HeLa cells due to induction of cellular damage control mechanisms. In conclusion, we propose that the essential oil had a more repressive effect on HeLa cells, decreases their proliferation and prevented the increase in the number of cells.
\end{abstract}

Keywords: Achillea millefolium, essential oil, apoptosis, cell cycle, proliferation, cervical cancer

'Erciyes University, Genome and Stem Cell Center (GENKÖK), Kayseri, Turkey

${ }^{2}$ Erciyes University, Institute of Natural and Applied Science, Kayseri, Turkey

${ }^{3}$ Erciyes University Faculty of Sciences, Kayseri, Turkey

*Corresponding author: S. Özcan E-mail: servet3@gmail.com, ozcan@erciyes.edu.tr

DOI: 10.2478/ebtj-2020-0003 (c) 2020 Authors. This work was licensed under the Creative Commons Attribution NonCommercial-NoDerivs 4.0 License.

\section{Introduction}

The genus Achillea is a member of the family Asteraceae (Compositae) and is distributed in different geographical regions of the world, being mainly present in Asia, Europe and America. There is a wide range of Achillea and 50 species belong to this genus in Turkey. One of them is Achillea millefolium $(1,2)$. A. millefolium, known as yarrow, is a perennial herbaceous plant that blooms between June and September.

A. millefolium is an aromatic and medicinal plant. Yarrow is applied in traditional medicine, mixed with tea or given in different types of consumption. Applications of yarrow in traditional medicine can be exemplified in kidney diseases, wound treatment, urinary tract infections, cancer and gynecological diseases. Yarrow essential oil is important supplementary material in the treatment of oncogenic diseases and antimicrobial or antifungal infections (3). In the essential oil of the yarrow, there are more than one hundred bioactive compounds such as camazulene, $\alpha$ pinene, $\beta$ pinene, casticin, 1,8-cineole, cosmosiin and luteolin (1). Different compounds of yarrow's essential oil were applied on cancer cell lines; Casticin flavonoid obtained from A. millefolium have anti-tumor activity since it arrests cell cycle in G2 / M phase (4). Furthermore, 1.8 cineole and essential oil of Artemisia lavandulifolia were found to have some biological effects on KB oral epidermoid carcinoma cells, and Kim et al. (2010) indicated that this substance induces endonucleolytic DNA cleavage depending on the essential oil dose applied to the cells (5). There are similar studies conducted on different cancer cell lines investigated the anticancer effect of the yarrow essential oil $(6,7,8)$. It has been reported that different concentrations 
of hydroethanolic extract of A. millefolium were affective on cell cycle, apoptosis and inhibit the growth of NCI-H460 and HCT-15 cancer cell lines (6). Additionally, another member of genus Achillea, A. falcata, extract had an antiproliferative effect, and this extract induced cellular apoptosis and formation of apoptotic bodies in HeLa cell line (7). For instance, Lamia et al. have demonstrated that yarrow's essential oil plays a role as a complementary adjuvant in pancreatic cancer (8).

Although there are some studies using the essential oil of A. millefolium on cancer cell lines, the link between the compound and the molecules which play a role in cancer related networks, is scarce. The aims of this study were i) to investigate the effects of different concentrations of essential oil obtained from the yarrow plant (A. millefolium) on HeLa cells, and ii) to show the biological pathways of the components of the yarrow plant in network analysis.

\section{Material and Methods \\ Preparation of the Achillea millefolium (ACH) essential oil for the treatment}

Yarrow was collected from its habitats near Kayseri Ali mountain (a registered example is CV4851, Erciyes University Herbarium). Collected plants were dried at room temperature. After weighing of the dried plant, about 10 times more water was added (i.e. 1 liter per 100 grams). Distillation method was applied as described in the procedure of Raal et al (2006) to obtain essential oils (9). The essential oils extracted were stored at $4{ }^{\circ} \mathrm{C}$ for cell culture analysis. $500 \mu \mathrm{L}$ of the essential oil of $A$. millefolium was prepared for GC-MS analysis. In order to apply to cell culture, essential oil was dissolved in DMSO $(1: 10 \mathrm{v} / \mathrm{v})$.

\section{GC-MS analysis}

$500 \mu \mathrm{L}$ of the essential oil was prepared for GC-MS analysis (Shimadzu-QP2010 ULTRA). The analysis were performed at Bozok University Science and Technology Application and Research Center. GC analysis was performed on SLB-5m colum (Spelco, Milan, Italy). Oven temperature was from 50 to $280^{\circ} \mathrm{C}$ with an increments of $4{ }^{\circ} \mathrm{C}$ per min, as the carrier gas Helium being used in flowrate of $2 \mathrm{~mL}$ per min. $\mathrm{C}_{5}-\mathrm{C}_{24}$ n-alkane library library was used to identify the spectras. In order to establish a link between cancer cells and the molecules, the function of the GC-MS identified compounds was investigated by Ingenuity Pathway Analysis (IPA, QIAGEN) software.

\section{Cell culture}

In this study, we used ATCC HeLa (CCL-2) cell line to investigate the anticancerogenic effect of essential oil. HeLa cells were cultured in RPMI-1640 (Biological Industries) medium containing 10\% FBS (Biological Industries), 1\% L-glutamine (Biological Industries) and $1 \%$ penicillin-streptomycin (Biological Industries). A. millefolium essential oils were dissolved in DMSO following at $1: 10(\mathrm{v} / \mathrm{v})$ dilution. $0.05 \%, 0.1 \%, 0.5 \%$ $(\mathrm{v} / \mathrm{v})$ essential oil in DMSO were added on culture media and $0.5 \%, 1 \%$ and $5 \%(\mathrm{v} / \mathrm{v})$ DMSO blank groups were used as control. Since the essential oil is poorly soluble, it was dissolved in high percentage of DMSO. Keeping in mind that high concentration of DMSO is also toxic to the cells, therefore keeping the DMSO level below 5\% was the main purpose. After 48 hours incubation, biological tests were performed.

\section{Biological effects of Achillea millefolium (ACH) essential oil application Apoptosis assay}

For the apoptosis assay, MUSE Annexin V / Dead Cell kit was used. After the essential oil application, HeLa cells were liberalized by trypsinization and dissolved in $100 \mu \mathrm{L}$ of DPBS with $2 \%$ FBS. $100 \mu \mathrm{L}$ of Annexin V and Dead Cell Reagent were added on suspension and incubated for 20 minutes. The analyses were performed by using MUSE ${ }^{\mathrm{TM}}$ Cell Analyzer (Merck, Germany).

\section{Cell Cycle assay}

HeLa cells were dissolved in $100 \mu \mathrm{L}$ of $2 \%$ FBS containing DPBS and test groups were fixed with $70 \%$ ethanol in and incubated at $-20^{\circ} \mathrm{C}$ overnight. In the following step, ethanol was removed by centrifugation and $100 \mu \mathrm{L}$ of PI (Propodeum iodide)-containing dye was added. After 30 minutes incubation, cells were analyzed by using MUSE ${ }^{\mathrm{TM}}$ Cell Analyzer.

\section{Proliferation assay}

In order to complete Ki-67 proliferation assay, HeLa cells were dissolved in $100 \mu \mathrm{L}$ DPBS containing 2\% FBS and washed by centrifugation. Cells were fixed with $4 \%$ paraformaldehyde at room temperature for 15 minutes. In order to get rid of the fixative solution, cells were washed with assay buffer. Fixed cells were incubated with permeabilization buffer and washed with assay buffer once. Phycoerythrin (PE)-conjugated Ki-67 antibody was added to cells and incubated for 30 mins. PE-conjugated $\mathrm{Hu}-\mathrm{IgG}$ were used as isotype control during threshold determination. Analyses was completed by using the MUSE ${ }^{\mathrm{TM}}$ Cell Analyzer.

\section{Statistical analysis}

In statistical calculations, the changes of the experimental groups according to the control groups were compared by using One-Way Anova Test. Post-Hoc Tukey test was applied to determine the general differences, multiple comparisons were made. The results were determined according to mean \pm standard deviation $(\mathrm{X} \pm \mathrm{SD})$ and showed a statistical significance of $\mathrm{p}<0.05$ SPSS (16.0-2010) package program was used in all calculations.

\section{Results}

\section{Component analysis of essential oil by GC-MS}

In GC-MS analysis, 10 different major molecules were identified from yarrow essential oil. Retention time and peak area percentage were provided at Peak report total ion chromatography table (Table 1 ).

The three compounds were more dominant than rest of other compounds in essential oil. These dominant yarrows essen- 
Table 1. GC-MS analysis of essential oil components from A. millefolium. According to Peak report 10 different molecule were identified in essential oil. Four of these molecules are significantly higher than other molecules.

\begin{tabular}{|c|c|c|c|c|}
\hline \multicolumn{5}{|c|}{ Peak Report Total Ion Chromatogram } \\
\hline Peak \# & Molecule & R. Time & Area & Area \% $\downarrow$ \\
\hline 3 & 1,8-Cineole & 8.127 & 83328771 & 27.34 \\
\hline 4 & Camphor (CAS) & 9.585 & 74017016 & 24.28 \\
\hline 10 & .beta.-Eudesmol (CAS) & 14.158 & 57129364 & 18.74 \\
\hline 8 & Caryophyllene oxide & 13.595 & 25349728 & 8.32 \\
\hline 5 & Bicyclo[2.2.1]heptan-2-ol. 1.7.7-trimethyl-, (1S-endo)- & 9.832 & 16313677 & 5.35 \\
\hline 1 & Camphene & 7.053 & 10954991 & 3.59 \\
\hline 9 & Viridiflorol & 13.681 & 10656458 & 3.50 \\
\hline 2 & Bicyclo[3.1.1] heptan. 6.6-dimethyl-2-methylene-. (1S)- & 7.424 & 9919490 & 3.25 \\
\hline 7 & .alpha.-Terpineol & 10.005 & 8602416 & 2.82 \\
\hline \multirow[t]{2}{*}{6} & 3-Cyclohexen-1-ol. 4-methyl-1-(1-methylethyl)-. (R)- & 9.880 & 8528233 & 2.80 \\
\hline & & & 304800144 & 100.00 \\
\hline
\end{tabular}

tial oil content was determined as 1.8 cineole $(27.4 \%)$, Camphor $(24.28 \%)$ and $\beta$-Eudesmol (18.74\%). Additionally with the chemically similar structure carrying compound, Camphene $(3.9 \%)$, medically noticeable, were also been detected. Although we analyzed all identified compounds of essential oil, only four of the all compunds were recognized by IPA databases. Therefore the biological effects of these four molecules (1,8-Cineole, Camphor, $\beta$-Eudesmol and Camphene) were analyzed by using Ingenuity Pathway Analysis software for the network analysis. Data obtained from these four biomolecules were evaluated in terms of biological significance and related canonical pathways were determined.

Our results indicated that the major 4 molecules in essential oil have potential to influence various pathway and network which were crucial for cellular metabolism and viability. Most important of these pathways were cAMP, Protein Kinase A (PKA), AMPK, MAPK, ATM and Apoptosis Signaling Pathways. IPA results also showed that the components of essential oil can influence Type II Diabetes signaling, Superoxide radical degradation process and estrogen biosynthesis (Fig. 1).
A.

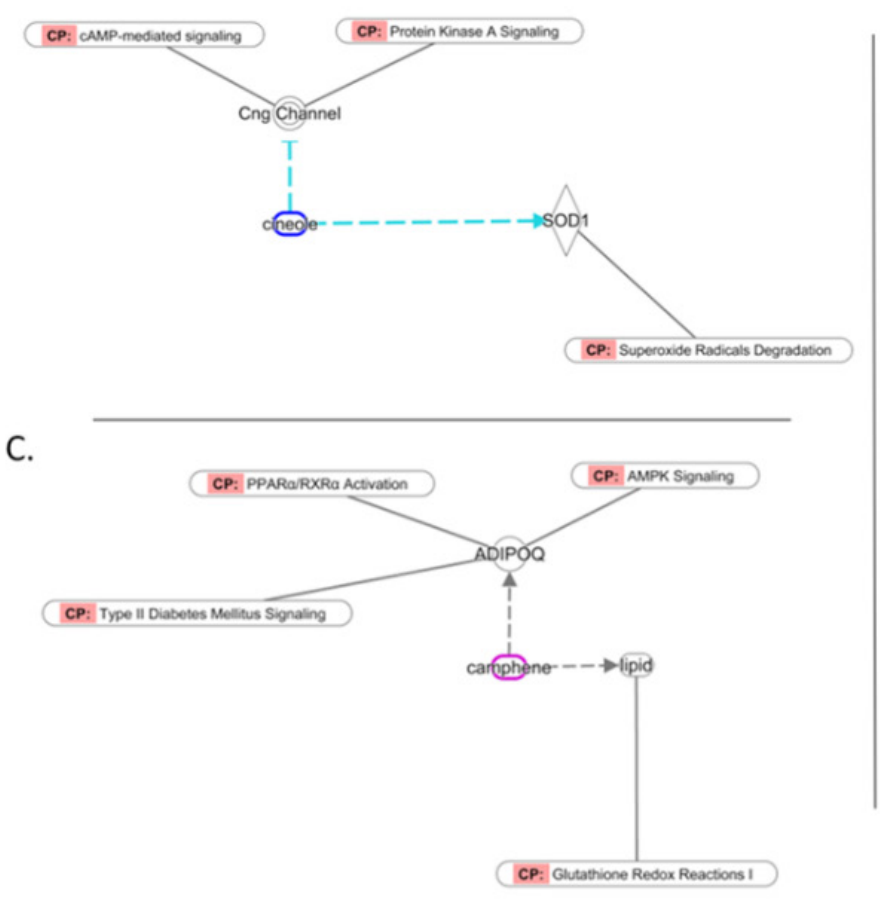

B.
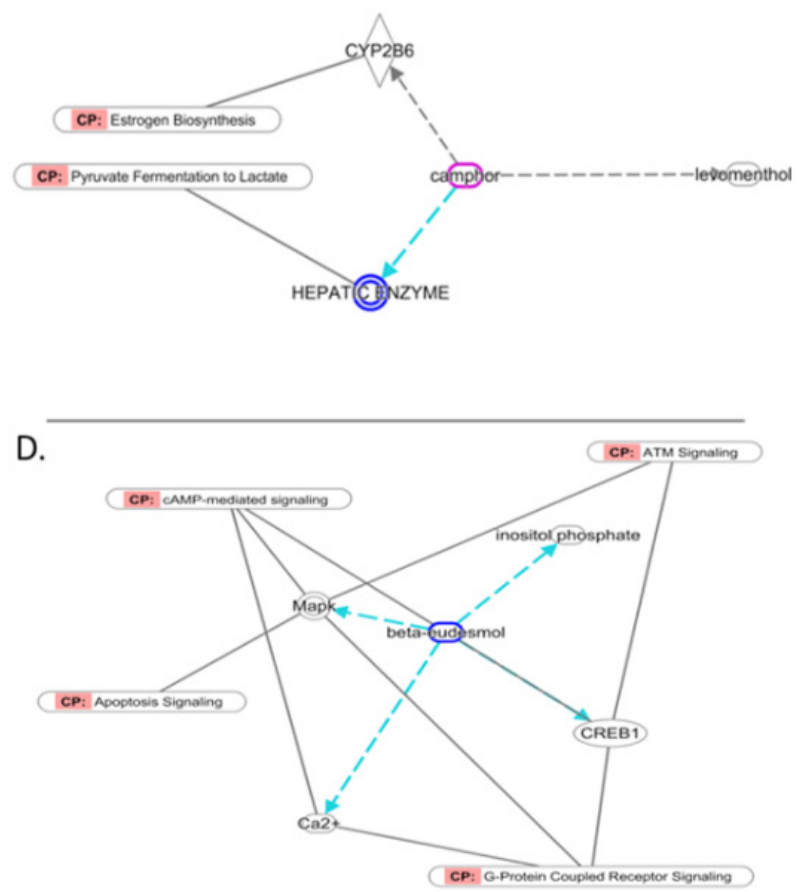

Figure 1. Ingenuity Pathway Analysis software for the network analysis for the most abundant four molecules (1,8-Cineole, Camphor, $\beta$-Eudesmol and Camphene). Compound related networks were depicted in A, B, C and D, respectively. 


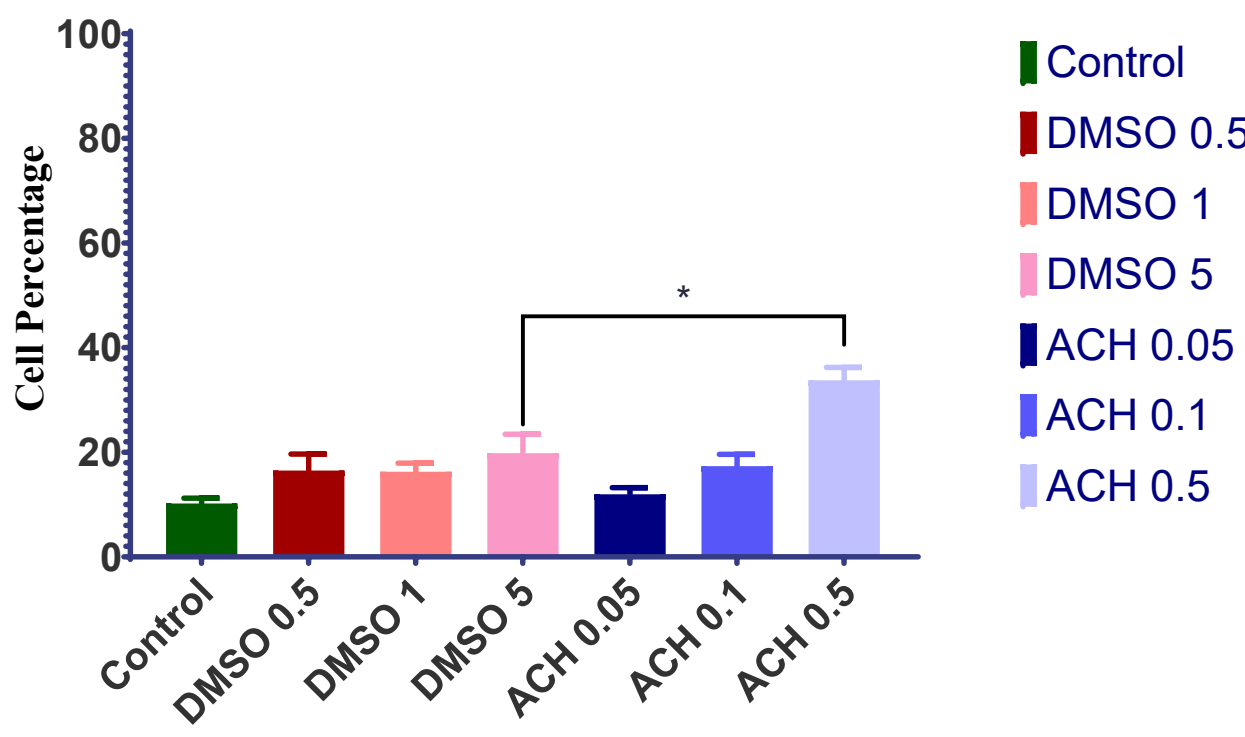

Figure 2. Annexin V / 7-AAD test results total apoptosis rates for HeLa cell line. In comparison with DMSO control group essential oil shows apoptotic effects on cancer cell line.

Following IPA analysis, it was determined that cineole molecule blocks the Cng channel and increases the expression of Superoxide Dismutase 1. The Cng channel is associated with cAMP signaling pathway and Protein Kinase A pathway. (B.) it was found that the camphor molecule increased the expression of some hepatic enzymes associated with the Pyruvate fermentation and increased expression of the CYP2B6 molecule related to estrogen biosynthesis. (C.) Camphene molecule increased the expression of the ADIPOQ molecule associated with PPARa/RXRa Activation and Glutathione Redox Reactions. Adiponectin also is closely associated with AMPK signaling pathway and Type II Diabetes signaling pathway. (D.)

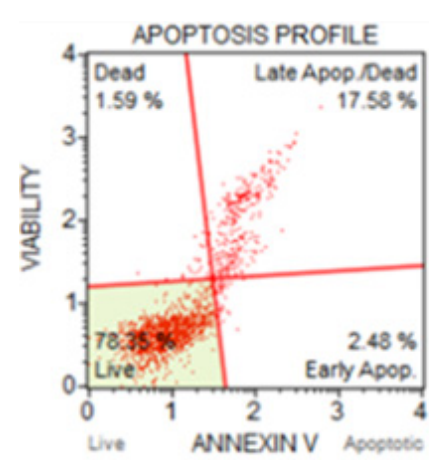

DMSO 0,5

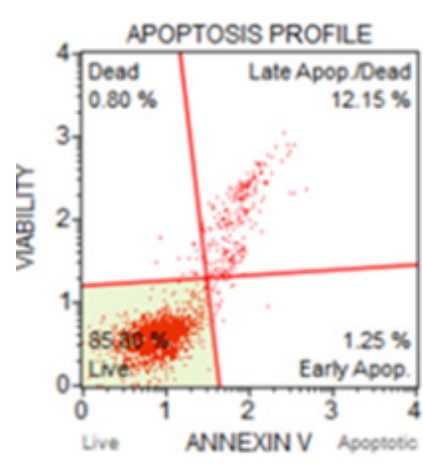

$\mathrm{ACH} 0,05$

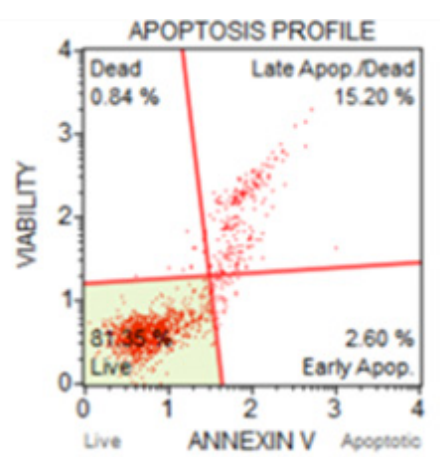

DMSO 1

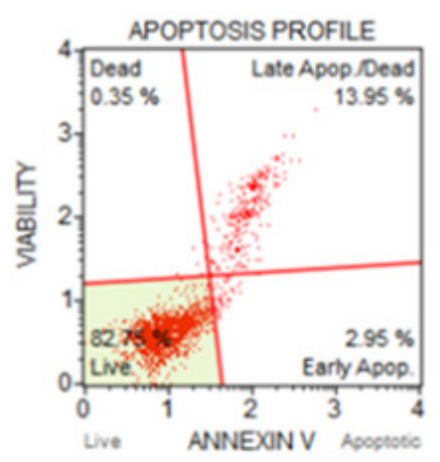

$\mathrm{ACH} 0,1$

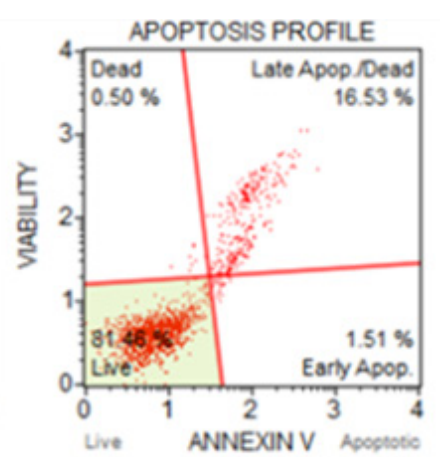

DMSO 5

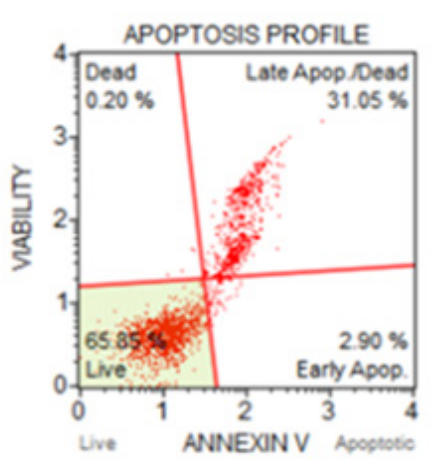

$\mathrm{ACH} 0,5$

Figure 3. Yarrow essential oils treatment results as Dot-Plot on HeLa cell line. Number of healthy cells were decreased after essential oil treatment and apoptotic and dead cell percentage were increased. 


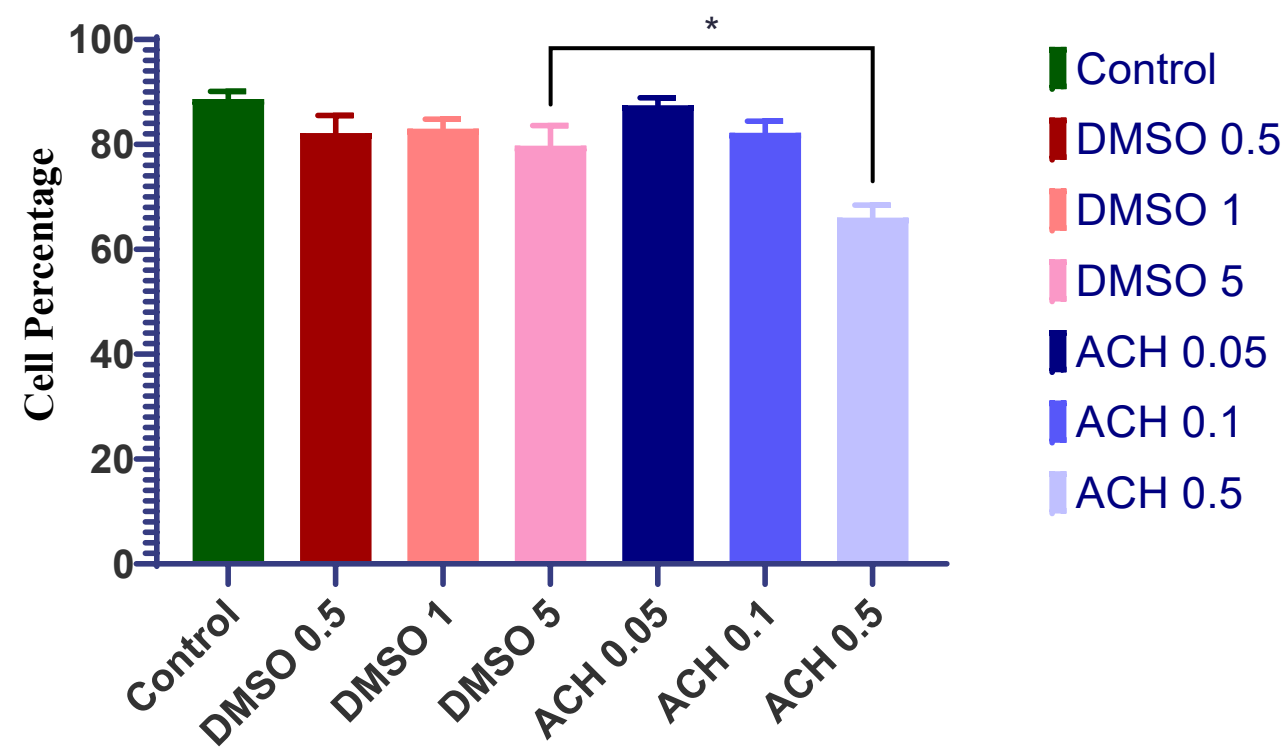

Figure 4. Annexin V / 7-AAD test and live cell percentage of HeLa cells. Number of living cells were decreased significantly when compared DMSO control group.

$\beta$-Eudesmol molecule influences the cAMP, ATM, Apoptosis and GPCR signaling pathways through MAPK, inositol phosphate, Calcium and CREB1.

Biological analysis of cervical cancer (HeLa cell line) cells treated with essential oil

\section{Apoptosis assay}

It was observed that $A$. millefolium essential oil application induced apoptosis in HeLa cells. While the rate of apoptosis was $20 \%$ in the DMSO control group, the ratio was increased to $34 \%$ in the ACH treatment group (Fig. 2 and Fig. 3 ).

This ratio of apoptotic cells was found statistically significant $(\mathrm{p}<0.05)$ between the application of $0.5 \%$ essential oil and DMSO control. It was observed that $0.5 \%$ essential oil applica- tion was successful in inducing apoptosis in HeLa cells compared to other doses.

When applied, the A. millefolium essential oil decreased the viability of HeLa cells (Fig. 4). The $80 \%$ cell viability in the DMSO control group decreased to $60 \%$. This difference was found statistically significant $(\mathrm{P}<0.05)$. The differences between the other doses and DMSO controls were not significant.

\section{Cell Cycle analysis}

According to the results obtained from the cell cycle test, the high amount of DMSO blocks the cells in the G0/G1 phase. Difference between $\mathrm{ACH}$ and DMSO control groups were found to be significant $(\mathrm{P}<0.05)$. The current results indicated that $0.5 \%(\mathrm{v} / \mathrm{v})$ A. millefolium essential oil concentration

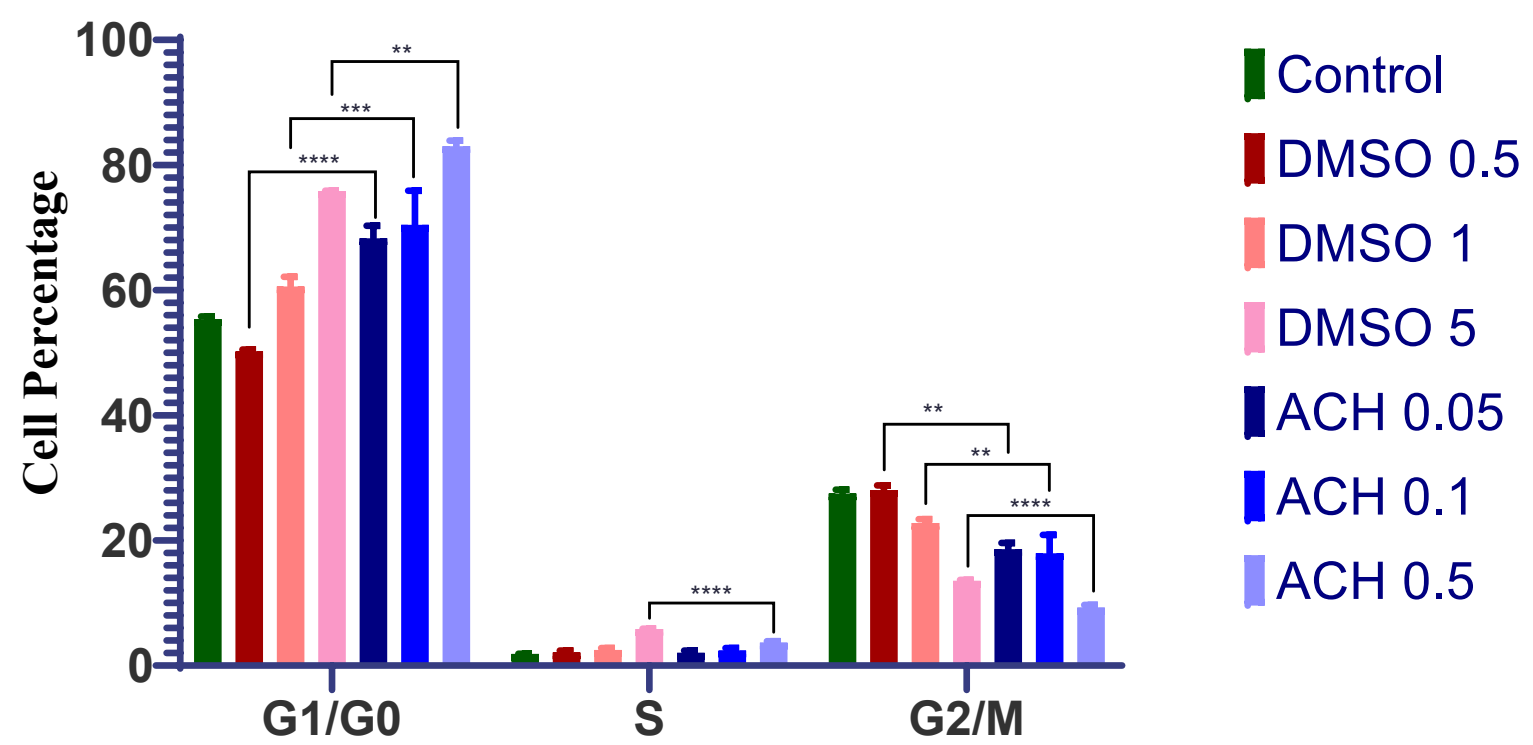

Figure 5. Cell cycle test for HeLa cell line. Essential oil application blocks the cell cycle in G0/G1 phase when compared DMSO control group. 


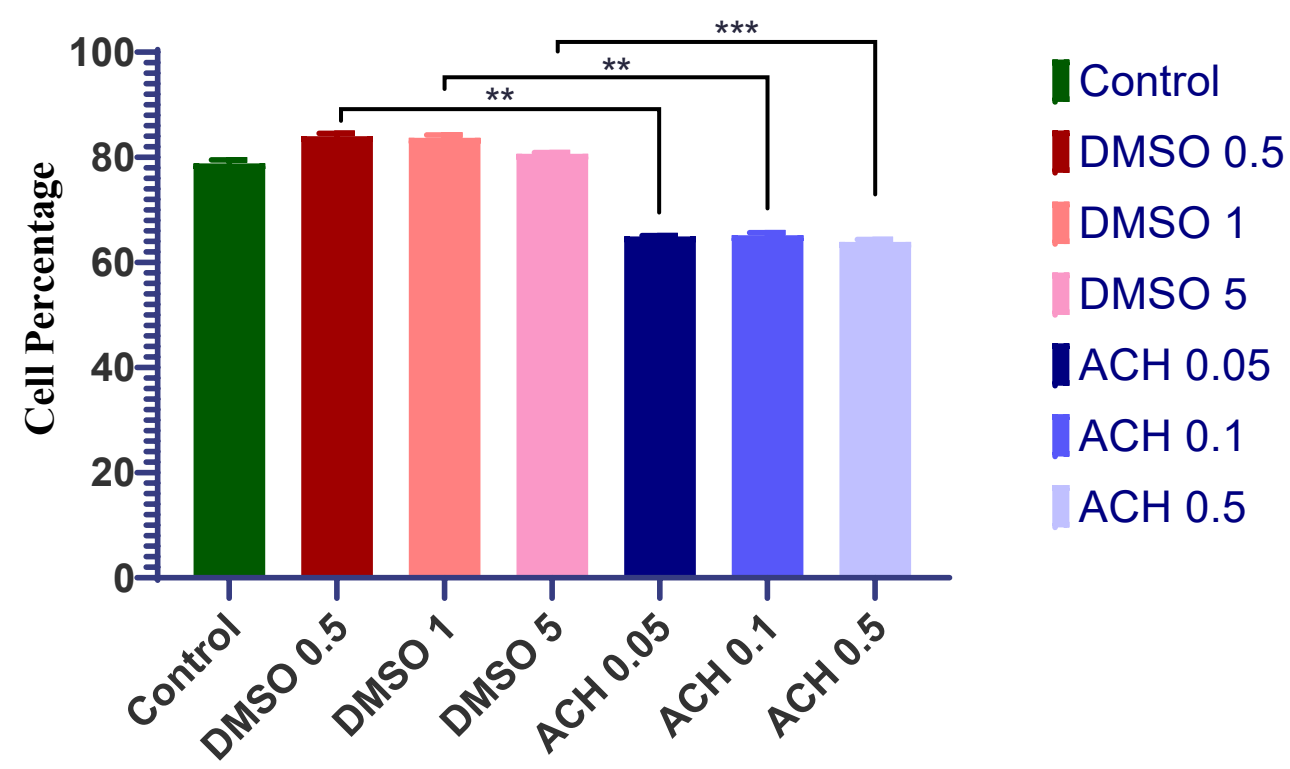

Figure 6. Ki-67 test and proliferating cell (+) ratios for HeLa cell line. Ki-67 proliferation test shows in correlation with cell cycle tests essential oil application inhibits the proliferation of cervix cancer cells in all concentration.

was more effective when compared with control groups (Fig. 5). According to cell cycle data number of cycling cell was decreased after essential oil application.

\section{Cell proliferation analysis}

The results of Ki-67 test showed that the application of essential oil decreased the proliferation of HeLa cells when compared to the control groups (Fig. 6 and Fig. 7). The data was statistically significant $(\mathrm{P}<0.05)$. This showed that the application of essential oil to HeLa cells might prevent the proliferation of cancer cells.

Our study indicated that the components present in yarrow
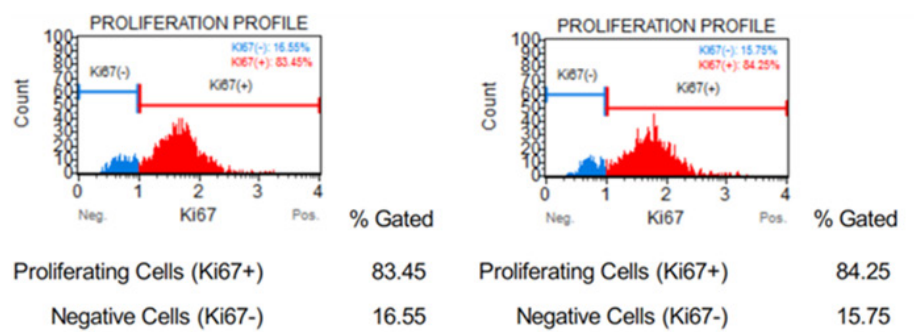

DMSO 0,5

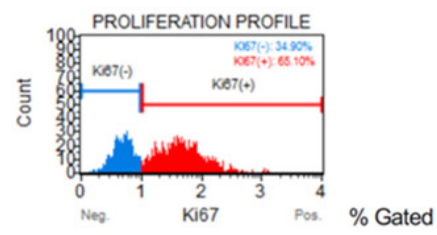

Proliferating Cells (Ki67+)

Negative Cells (Ki67-)

65.10

34.90
83.45

Proliferating Cells (Ki67+)

Negative Cells (Ki67-)

DMSO 1

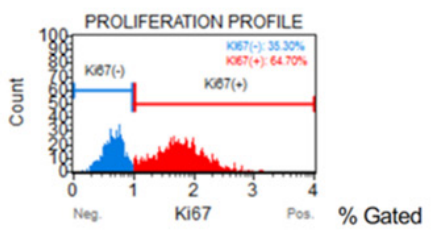

Proliferating Cells (Ki67+)

Negative Cells (Ki67-)

64.70
35.30

$\mathrm{ACH} 0,1$ essential oil were associated with various molecular mechanisms. The mixture of these compounds induced apoptosis and inhibited cell proliferation by reducing proliferation in HeLa cells. It has been shown that one or more of the components in yarrow essential oil might have anticancer properties (10).

\section{Discussion}

Various plants have been used medical purpose and applied for different treatments in traditional medicine. The components of the essential oils of plants are shown to be effective in complementary and alternative therapy (1). Some of the wellknown components in the essential oils of medicinal plants are

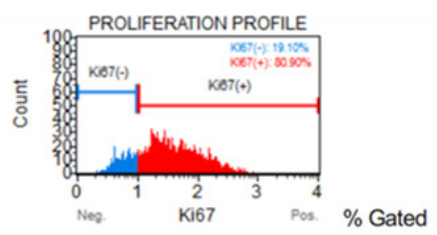

$\begin{array}{rr}\text { Proliferating Cells (Ki67+) } & 80.90 \\ \text { Negative Cells (Ki67-) } & 19.10\end{array}$

DMSO 5
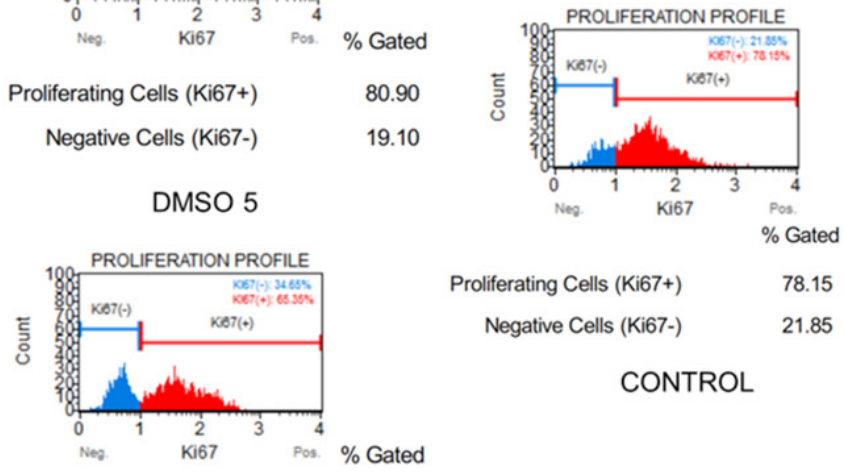

Proliferating Cells (Ki67+) $\quad 78.15$ Negative Cells (Ki67-) $\quad 21.85$

CONTROL

Proliferating Cells (Ki67+) $\quad 65.35$

Negative Cells (Ki67-) $\quad 34.65$

$\mathrm{ACH} 0,5$

Figure 7. Proliferating cell percentage as Volcano Plot graph of HeLa cells in Control, DMSO Control and ACH groups. According to Ki-67 Proliferation Assay results proliferation of cells blocked by essential oil of A. millefolium. 
monoterpenes and derivatives having a property of anticancer agent that are used in chemotherapy. There are examples of the medical uses of yarrow for complementary and alternative therapies that are related to cancer, diabetes, atherosclerosis and metabolism (11).

In this study, GC-MS analysis detected the presence of monoterpene, sesquiterpene and terpenes in the essential oil of A. millefolium. In order to establish a link between the biological effect of A. millefolium essential oil and medical purposes, IPA analysis were performed. The compounds of essential oil (1,8-cineole, camphor, camphene and beta-eudesmol) were in relation with some molecular pathways, which have important role in cellular functions and metabolism. When considering IPA analysis, it was concluded that the 1,8-cineole molecule directly related to the Superoxide dismutase (SOD) level, which means that $A$. millefolium has an important antioxidant activity, especially it helps to break down the superoxide radical caused by mitochondrial oxidation. A recent study provided that Achillea alexandri-regis plant extract has antioxidant effects on the HeLa cell line (12). As shown in the study of Kundakovic et al. (2005), other members of the genus Achillea could have similar antioxidant activity like $A$. alexandri-regis. In addition, 1,8-cineole has been in relation with the Protein Kinase A (PKA) signaling pathway and cAMP secondary messenger signaling pathways. Previous studies indicated that the cineole molecule triggers the production of cAMP and inositol 3-phosphate (13), we also determined similar activity with our IPA analysis (Fig. 1A).

In our GC-MS analysis, camphor molecule was found to be the second most abundant ones. According to IPA analysis, it was detected that camphor was related to the expression of CYP2B6 molecule (Fig. 1B). The CYP2B6 molecule is associated with estrogen biosynthesis and is similar to estrogenic activity of that in the MCF-7 cell line. Extract of the above-ground portions of $A$. millefolium was demonstrated to have estrogenic activity on the MCF-7 cell line (14). The ability to increasing the level of estrogen related molecule CYP2B6, it could be considered a significant finding especially observed effect on cervix cancer cell line HeLa and it is suggesting that it should be investigated by further studies.

Considering IPA analysis, $\beta$-Eudesmol was determined to be affecting G-protein mediated receptor pathways, calcium and inositol 3-phosphate secondary messenger pathways and MAPK pathway (Fig. 1D). Some studies in the literature have shown that $\beta$-Eudesmol induces apoptosis via c-Jun $\mathrm{N}$-terminal Kinases (JNK), which are associated with the MAPK signalling pathway (15). Additionally, $\beta$-Eudesmol molecules can induce apoptosis in hematopoietic cancer cell lines and hepatocellular carcinoma cell lines (16). Since $\beta$-Eudesmol is an effective molecule on ATM, ATR kinases and apoptosis signal, essential oil applied cells must be evaluated in terms of cell cycle and apoptotic properties as already done with our study. Furthermore, the relation of $\beta$-Eudesmol with the cAMP mediated signalling pathway and the GPCR signalling pathway were enhancing the value to this molecule in terms of various cell signalling mech- anism like glucagon metabolism, inflammatory response, epinephrine prostaglandin etc.

Another molecule identified by GC-MS analysis was the camphene. A recent study showed the antidiabetic effect of $A$. millefolium extracts (17). In our work, camphene molecule effects the increasing in expression of ADIPOQ (Adiponectin), a protein with a regulatory role in glucose metabolism and fatty acid oxidation (Fig. 1C). In this case, camphene might have an important role in diabetes and obesity mediated diseases. If we consider the obesity as the reason of various disease leading to cancer, it can be mentioned that essential oil has also indirect anticancerogenic effects (18).

As a second part of study, we investigated the effects of essential oil on cervix cancer cell line HeLa. When apoptosis test performed on HeLa cells, ACH treatment at different concentrations increased the number of total apoptotic cells. The treatment of $0.5 \%(\mathrm{v} / \mathrm{v}) \mathrm{ACH}$ showed an approximately $15 \%$ increase in the percentage of apoptotic cells when compared to the control group, which containing the same amount of DMSO. Similarly, our results, the study by Bali et al. showed that the phenolic compounds containing $\mathrm{ACH}$ extracts increased the activation of apoptosis genes such as Bax and Cas3 in PC-3 cells (19). The viability of The number of HeLa cells was reduced about $10-15 \%$ with the treatment of $0.5 \%(\mathrm{v} / \mathrm{v})$ $\mathrm{ACH}$ essential oil. The aforementioned study done by Bali et al. (19) also tested membrane integrity that shares common grounds with the dead cell assay we conducted. In order to deeply investigate the essential oil effects on apoptosis pathway, it needs to be investigated the expression of certain genes such as Bax, Bad, Bcl2, and Cas3/7 at transcriptomic level in an extensive study.

We also observed that the application of essential oil blocked cell cycle of HeLa cells on G0/G1 phase of cycle. In accordance with cell cycle data, essential oil application reduced the expression of Ki-67, a marker for cell proliferation. Anti-proliferative properties of A. millefolium essential oil is well known since flavonoids and sesquiterpenes of $A$. millefolium have shown an inhibitory effect on the proliferation of HeLa and MCF-7 cancer cell lines (20). Both the literature and in this study, experimental results showed that essential oil of A. millefolium anti-proliferative effect on HeLa cancer cell line. For instance, investigation of cell cycle checkpoint genes and proteins with molecular approaches such as q-PCR, Western Blot or Mass Spectrometry studies could give crucial information about mechanism of action of essential oil.

Furthermore, individual analysis of identified molecules by GC-MS could lead valuable data that could be used for anticancerogenic drug discovery studies.

As a consequence, essential oil of A. millefolium have anti-proliferative and apoptotic effects on cervix cancer cell line HeLa. According to experimental and literature originated data it seems possible to use these compounds as therapeutic agents directly or cooperatively with chemotherapeutics for several disease including cervix cancer. 


\section{Conclusion}

Therapeutic effects of the yarrow essential oils were investigated on cervical cancer cell line, which is important for women's health (21). We reported that essential oil components may interact with molecular pathways that are closely related to cancers. The yarrow's essential oil has potential to induce apoptosis in HeLa cells and inhibit cell proliferation. It was found that at least one of the components of the essential oil have anticancer properties. Concurrently, components of the yarrow's essential oils should be subject to more detailed research. Examination of 1,8-Cineole, Camphor, Beta-eudesmol and Camphene molecules may provide valuable data to lead anti-cancer drug discoveries. Explaining the relationship of these components to molecules, which involved in disease-related mechanisms, may help complementary and alternative therapies.

\section{Acknowledgements}

We are grateful to Bozok University Science and Technology Application and Research Center for GC-MS analysis.

This study was partially supported by Erciyes University Scientific Research Project Department (ERU BAP- FBY-12-3935).

\section{Conflict of Interest}

The authors declare that they have no conflicts of interest.

\section{Ethical Compliance}

This article does not contain any studies involving human participants or animals performed by any of the authors.

\section{References}

1. Ali SI, Gopalakrishnan B, Venkatesalu V. Pharmacognosy, phytochemistry and pharmacological properties of Achillea millefolium L.: A review. Phytother Res 2017; 31(8): 1140-1161.

2. Çoşkunçelebi K. Hieracium. In: Guner A, Aslan S, Ekim T, Vural M, Babaç M T(eds.). Türkiye bitkiler Listesi (Damarlı Bitkiler). Nezahat Gökyiğit Botanik Bahçesi ve Flora Araştırmaları Derneği Yayını 2012; 110-111.

3. Nemeth E, Bernath J. Biological activities of yarrow species (Achillea spp.). Curr. Pharm. Des 2008; 14(29): 3151-3167.

4. Haïdara K, Zamir L, Shi QW, Batist G. The flavonoid Casticin has multiple mechanisms of tumor cytotoxicity action. Cancer Lett 2006; 242(2):180-190.

5. Cha JD, Kim YH, Kim JY. Essential oil and 1, 8-cineole from Artemisia lavandulaefolia induce apoptosis in KB cells via mitochondrial stress and caspase activation. FSB 2010;19(19): 185-191.

6. Pereira JM, Peixoto V, Teixeira A, Sousa D, Barros L, Ferreira IC, Vasconcelos MH. Achillea millefolium L. hydroethanolic extract inhibits growth of human tumor cell lines by interfering with cell cycle and inducing apoptosis. FCT 2018; 118: 635-644.

7. TIAN Qing, ZANG Yong-Hong. Antiproliferative and apoptotic effects of the ethanolic herbal extract of Achillea falcata in human cervical cancer cells are mediated via cell cycle arrest and mitochondrial membrane potential loss. J BUON 2015; 20(6): 14871496.

8. Mouhid L, de Cedrón MG, García-Carrascosa E, Reglero G, Fornari T, de Molina AR. Yarrow supercritical extract exerts antitumoral properties by targeting lipid metabolism in pancreatic cancer. PloS one 2019; 14(3): e0214294.

9. Orav A, Arak E, Raal A. Phytochemical analysis of the essential oil of Achillea millefolium L. from various European Countries. Nat. Prod. Res 2006; 20(12): 1082-1088.

10. Bozkurt-Guzel C, Serbetci T, Kultur S. Cytotoxic activities of some Turkish medicinal plants against HeLa cells in vitro. 2018.

11. Edris AE. Pharmaceutical and therapeutic potentials of essential oils and their individual volatile constituents: a review. Phytother Res 2007; 21(4): 308-323.

12. Kundaković $T$, Stanojković $T$, Juranić $Z$, Kovačević N. Cytotoxic and antioxidant activity of Achillea alexandri-regis. Die PharmazieIJPS 2005; 60(4): 319-320.

13. Barry PH. The relative contributions of CAMP and InsP3 pathways to olfactory responses in vertebrate olfactory receptor neurons and the specificity of odorants for both pathways. JGP 2003; 122(3): 247-250.

14. Innocenti G, Vegeto E, Dall'Acqua S, Ciana P, Giorgetti M, Agradi E, Tomè F. In vitro estrogenic activity of Achillea millefolium L. Phytomedicine 2007 ; 14(2-3): 147-152.

15. Li Y, Li T, Miao C, Li J, Xiao W, Ma E. $\beta$-Eudesmol induces JNK-dependent apoptosis through the mitochondrial pathway in HL60 cells. Phytother Res 2013; 27(3): 338-343.

16. Bomfim DS, Ferraz RP, Carvalho NC, Soares MB, Pinheiro ML, Costa EV, Bezerra DP. Eudesmol Isomers Induce Caspase-Mediated Apoptosis in Human Hepatocellular Carcinoma Hep G 2 Cells. Basic Clin Pharmacol Toxicol 2013;113(5): 300-306.

17. Chávez-Silva F, Cerón-Romero L, Arias-Durán L, Navarrete-Vázquez G, Almanza-Pérez J, Román-Ramos R, Estrada-Soto S. Antidiabetic effect of Achillea millefollium through multitarget interactions: a-glucosidases inhibition, insulin sensitization and insulin secretagogue activities. J ethnopharmacol 2018; 212: 1-7.

18. Nigro E, Scuderio O, Monaco ML, Palmeri A, Mazzarella G, Costaglioa C, Daniele A. New insight into adiponectin role in obesity and obesity related disease. BioMed Res Int. 2014; 658913.

19. Bali EB, Açık L, Elçi P, Sarper M, Avcu F, Vural M. In vitro antioxidant, cytotoxic and pro-apoptotic effects of Achillea teretifolia Willd extracts on human prostate cancer cell lines. Pharmacognosy magazine 2015; 11(2): S308.

20. Csupor-Löffler B, Hajdú Z, Zupkó I, Réthy B, Falkay G, Forgo P, Hohmann J. Antiproliferative effect of flavonoids and sesquiterpenoids from Achillea millefolium sl on cultured human tumour cell lines. Phytother Res 2009; 23(5): 672-676.

21. ROMM, Aviva. Botanical Medicine for Women's Health E-Book. Elsevier Health Sciences, 2017. 